\title{
Paris saponin I induces apoptosis via increasing the Bax/Bcl-2 ratio and caspase-3 expression in gefitinib-resistant non-small cell lung cancer in vitro and in vivo
}

\author{
HAO JIANG $^{1 *}$, PENG-JUN ZHAO ${ }^{2 *}$, DAN SU $^{3}$, JIANGUO FENG ${ }^{3}$ and SHENG-LIN MA ${ }^{4}$ \\ ${ }^{1}$ Department of Oncology, Zhejiang Hospital, Hangzhou, Zhejiang 310013; ${ }^{2}$ Department of Radiation Oncology, \\ Hangzhou Cancer Hospital, Hangzhou, Zhejiang 310002; ${ }^{3}$ Department of Oncology, Cancer Institute, \\ Zhejiang Cancer Hospital, Hangzhou, Zhejiang 310022; ${ }^{4}$ Department of Oncology, Cancer Institute, \\ Hangzhou First People's Hospital, Hangzhou, Zhejiang 310006, P.R. China
}

Received August 23, 2013; Accepted March 7, 2014

DOI: $10.3892 / \mathrm{mmr} .2014 .2108$

\begin{abstract}
Polyphyllins, a major component of Rhizoma paridis, have been extensively used in non-small cell lung cancer (NSCLC). The aim of the present study was to evaluate the effects of Paris saponin I (PSI) on a panel of gefitinib-resistant NSCLC cell lines and its inhibition of tumor growth in a nude mouse model. The MTT assay was used to assess growth inhibition. The cell cycle was analyzed using flow cytometry and apoptosis was assessed using Annexin V/propidium iodide staining. The morphology of the apoptotic cells was determined by transmission electron microscopy. The protein expression levels of B-cell lymphoma 2 (Bcl-2), Bcl-2-associated X protein (Bax) and caspase-3 were detected using western blot analysis. In addition, the glucose metabolism in tumor-bearing mice was evaluated using ${ }^{18} \mathrm{~F}$-fludeoxyglucose (FDG) micro-positron emission tomography imaging. The PSI-induced growth inhibition rate was observed to significantly increase in a time- and dose-dependent manner. Furthermore, PSI induced significant G2/M-phase arrest and apoptosis. The expression levels of Bcl-2 decreased, while those of Bax and caspase-3 increased following PSI treatment. ${ }^{18} \mathrm{~F}-\mathrm{FDG}$-uptake in the PSI treatment groups was significantly decreased compared with that in the control group in vivo. In conclusion, PSI is a potent antitumor agent that acts by inhibiting the proliferation of gefitinib-resistant cells, and has potential as a candidate for a natural drug for gefitinib-resistant therapy. PSI-induced apoptosis, which occurred via multiple pathways, including
\end{abstract}

Correspondence to: Dr Sheng-Lin Ma, Department of Oncology Institute, Hangzhou First People's Hospital, 261 Huansha Road, Hangzhou, Zhejiang 310006, P.R. China

E-mail:mashenglin@medmail.com.cn

${ }^{*}$ Contributed equally

Key words: Paris saponin I, non-small cell lung cancer, gefitinib resistance, microPET, apoptosis
G2/M-phase arrest and upregulation of the Bax/Bcl-2 ratio and caspase-3 expression, ultimately led to cell death and tumor inhibition.

\section{Introduction}

Lung cancer has become one of the leading causes of cancer-related mortality worldwide, and the most common form, non-small cell lung cancer (NSCLC), accounts for $80-85 \%$ of these cases (1). Clinical chemotherapy, particularly with platinum-based chemotherapy regimens, can prolong survival and improve the quality of life in patients with advanced NSCLC; however, the overall prognosis remains unsatisfactory. With the development of oncology, molecular targeted therapeutic drugs have become widely used and are, at present, the clinical treatment of choice for advanced NSCLC. The use of molecular selection markers, other than epidermal growth factor receptor (EGFR) mutation testing for EGFR-tyrosine kinase inhibitor (TKI) treatment assignment, remains speculative at present, particularly for patients who have already undergone first-line chemotherapy for advanced stages of the disease (2). However, clinical experience, clinical and metrological data and findings at the molecular biology level all indicate that the occurrence of resistance is a constraint on the further use of TKIs and represents a bottleneck (3).

Gefitinib is a small-molecule quinazoline derivative that was developed as a TKI of the EGFR (4). The EGFR is known to promote cell growth, functions as an oncogene and is expressed in up to $80-90 \%$ of NSCLC cases (5). Gefitinib has been shown to induce radiographic tumor regression in patients with NSCLC that persisted following chemotherapy (6). However, despite the significant responses to EGFR-TKIs in patients with NSCLC with EGFR-activating mutations, de novo resistance to TKIs has been observed (7). Additional treatments for cases of NSCLC relapses following treatment with gefitinib are urgently required (8). Salvage chemotherapy has been shown to be less efficacious and is often at the expense of severe residual chemotherapy-related side effects (9). However, certain natural products are suitable alternatives that could be used for controlling cancer. In 
the past few decades, increasing attention has been focused on finding biologically active cancer therapeutic agents from natural resources (10).

Rhizoma paridis is the root of either Paris polyphylla Smith var. chinensis (Franch.) Hara or Paris polyphylla Smith var. yunnanensis (Franch.) Hand-Mazz. Rhizoma paridis has been reported to exert numerous pharmacological effects, including anti-inflammatory, hemostatic and anti-cancer effects, and was shown to exhibit inhibitory effects on tumor growth in numerous studies using hepatic, gastric or nasopharyngeal carcinoma models (11-16). Furthermore, Paris saponin II significantly inhibited tumor growth by $70 \%$ in the human SKOV3 ovarian cancer xenograft model (17), and Paris saponin $\mathrm{H}$ showed a marked cytotoxic activity on A549 cells with an $\mathrm{IC}_{50}$ value of $1.53 \pm 0.08 \mu \mathrm{g} / \mathrm{ml}$ (18). Paris saponin D has been shown to overcome drug resistance in R-HepG2 cells, elicit programmed cell death via mitochondrial dysfunction, inhibit endothelial cell functions in vitro and inhibit angiogenesis in zebrafish embryos in vivo $(19,20)$. Preclinical studies have made Paris saponins emerge as promising anti-cancer agents. Paris saponin I (PSI) has been demonstrated to exert a wide range of pharmacological activities and cytotoxicity against a number of malignancies, such as NSCLC, by increasing levels of B-cell lymphoma 2-associated X protein (Bax) and cytochrome $c$, activating caspase-3 and caspase-9, cleaving polymerase, and by decreasing B-cell lymphoma 2 (Bcl-2) expression levels and extracellular signal-regulated kinase-1/2 activity (21).

PSI has been approved for cancer therapy due to its potential involvement in the suppression of tumor growth. However, the effects of PSI in gefitinib-resistant NSCLC, with regard to increasing the $\mathrm{Bax} / \mathrm{Bcl}-2$ ratio and caspase-3 levels, have yet to be demonstrated in vitro. The aim of the present study was to focus on further investigating the effects of PSI on NSCLC with acquired gefitinib resistance in vitro and in vivo. The effects of PSI on a panel of gefitinib-resistant NSCLC cell lines were examined in vitro, and tumor glucose metabolism was evaluated in nude mice by micro-positron emission tomography (microPET) scanning in vivo.

\section{Materials and methods}

Drugs and reagents. PSI, which has a molecular formula of $\mathrm{C}_{44} \mathrm{H}_{70} \mathrm{O}_{16}$ (Fig. 1), was purchased at a purity of $>99 \%$ from the Zhejiang Institute for Food and Drug Control (batch no. 111590, Hangzhou, China). PSI was dissolved in dimethylsulfoxide (DMSO) as a $100 \mu \mathrm{g} / \mu 1$ stock solution and stored at $-20^{\circ} \mathrm{C}$. This was subsequently diluted in Dulbecco's Medium Eagle's medium (DMEM) to achieve the final concentration indicated for each experiment. DMEM and fetal calf serum were obtained from Hyclone Co. (Logan, UT, USA). Polyclonal rabbit anti-rat Bax antibody (P-19) and monoclonal mouse anti-rat Bcl-2 antibody, both at dilutions of 1:2,000, were obtained from Santa Cruz Biotechnology, Inc. (Santa Cruz, CA, USA) (22). Rabbit anti-rat caspase 3 polyclonal antibody, at a dilution of 1:25, was purchased from Abcam (Cambridge, MA, USA) (23). The fluorescein isothiocyanate (FITC) Annexin V Apoptosis Detection kit was from BD Biosciences (Franklin Lakes, NJ, USA). Cell culture flasks, as well as sixand 96-well cell culture plates, were from Corning Chemical

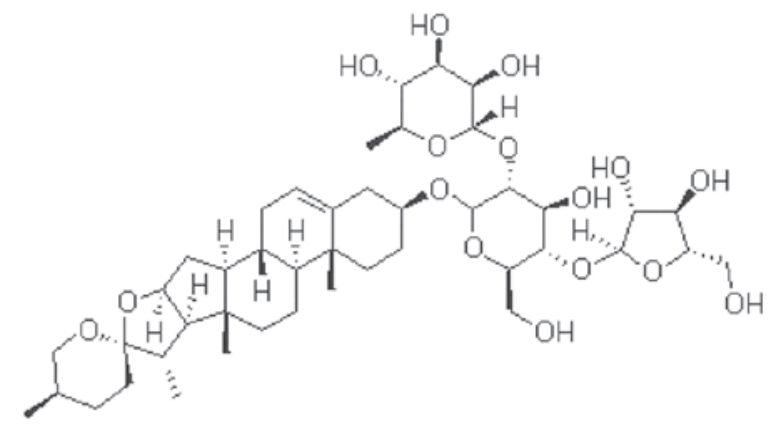

Figure 1. Chemical structure of Paris saponin I.

Co. (New York, NY, USA). All other chemical reagents were from Sigma Chemical Co. (St Louis, MO, USA).

Cell lines and culture. The gefitinib-resistant PC-9-ZD cell line was cultured in DMEM supplemented with $10 \%$ fetal bovine serum in a humidified incubator (Fischer Scientific, Inc., Houston, TX, USA) containing $5 \% \mathrm{CO}_{2}$ at $37^{\circ} \mathrm{C}$. PC-9-ZD cells were derived from human NSCLC PC-9 cells (derived from a patient with adenocarcinoma). The clone of a gefitinib-resistant cell line, known as 'PC-9-ZD', was selected following its development in gefitinib $(200 \mathrm{nmol} / \mathrm{l})$ for three months. PC-9-ZD cells were more resistant to gefitinib than their parental PC-9 cells (8).

Animals. Eight-week-old nude male mice, weighing $20.13 \pm 0.98 \mathrm{~g}$, were obtained from the Experimental Animal Center of Zhejiang Chinese Medical University (Hangzhou, China). Mice were housed in plastic cages with sterilized bedding in an air-conditioned room at $22 \pm 1^{\circ} \mathrm{C}$ and $51 \pm 4 \%$ humidity with a 12 -h light/dark cycle and access to filtered water and total nutrient feed. The experiments were performed in accordance with the national guidelines for animal care and use. The present study was approved by the ethics committee of Zhejiang Hospital (Hangzhou, Zhejiang, China).

MTT assay. The MTT colorimetric assay was performed to detect cell proliferation following exposure to PSI. Following harvesting by trypsinization, the PC-9-ZD cells (100 $\mu \mathrm{l} /$ well) were seeded in 96 -well plates at a density of $1 \times 10^{4}$ cells $/ \mathrm{ml}$. Each group had three wells with a nontreated group as the control. When the cells had attached to the plates, PSI was added at various concentrations $(0.5,1,2,3,4,5,6,7,8$ and $9 \mu \mathrm{g} / \mathrm{ml}$ ) and the plates were incubated at $37^{\circ} \mathrm{C}$ in a humidified atmosphere containing $5 \% \mathrm{CO}_{2}$. Following incubation for the indicated time intervals, $20 \mu 10.5 \%$ MTT was added to each well and cultured for a further $4 \mathrm{~h}$. The supernatant was discarded and the MTT formazan precipitate was dissolved in $150 \mu 1 \mathrm{DMSO}$, agitated for $10 \mathrm{~min}$ and then the absorbance (A) value was measured at $492 \mathrm{~nm}$ using a multiscanner autoreader. The following formula was used: Inhibition rate $(\%)=(1$-average $\mathrm{A}$ value of the experimental samples)/average A value of the control) x100.

Cell cycle analysis by flow cytometry. Following treatment with PSI $(1,2$ and $4 \mu \mathrm{g} / \mathrm{ml})$ and incubation for $48 \mathrm{~h}$, PC-9-ZD cells were collected. The cells were then resus- 
pended and fixed in $70 \%$ ice-cold ethanol overnight at $-20^{\circ} \mathrm{C}$. The next day, the cells were incubated in $10 \mu \mathrm{g} / \mathrm{ml} \mathrm{RNase}$ for $30 \mathrm{~min}$ at $37^{\circ} \mathrm{C}$ and then stained with $50 \mu \mathrm{g} / \mathrm{ml}$ propidium iodide (PI) for $1 \mathrm{~h}$ at $4^{\circ} \mathrm{C}$ in the dark. Cell cycle analysis was performed on a FACSCalibur flow cytometer (BD Biosciences) and the data were analyzed using CellQuest ${ }^{\mathrm{TM}}$ software (BD Biosciences). The experiments were repeated three times.

Assessment of apoptosis using flow cytometry. Apoptosis was examined by the Annexin-V/PI method. PC-9-ZD cells $(2 \mathrm{ml} /$ well $)$ were seeded into a six-well plate at a density of $1 \times 10^{4}$ cells $/ \mathrm{ml}$. Following treatment with PSI $(1,2$ and $4 \mu \mathrm{g} / \mathrm{ml}$ ) and incubation for $48 \mathrm{~h}$, the PC-9-ZD cells were collected and apoptosis was examined by using an Annexin V-FITC apoptosis detection kit (BD Biosciences), which detects phosphatidylserine exposed on the outer surface of the cell membrane. The cells were harvested with trypsin and washed with phosphate-buffered saline (PBS). Following centrifugation at $100 \mathrm{x} \mathrm{g}$, the supernatant was removed and the cells were suspended in a stain containing Annexin V-FITC and PI. The suspension was mixed and incubated at room temperature for $15 \mathrm{~min}$ in the dark. The cells were analyzed by FACSCalibur flow cytometry (BD Biosciences) within $1 \mathrm{~h}$ of staining. Data from $1 \times 10^{6}$ cells were collected for each data file. Apoptotic cells were defined as Annexin V-FITC-positive and PI-negative cells.

Morphology of apoptotic cells. Following incubation with 1, 2 and $4 \mu \mathrm{g} / \mathrm{ml}$ PSI for $48 \mathrm{~h}$, PC-9-ZD cells were collected and centrifuged at $400 \mathrm{x} \mathrm{g}$ to obtain a pellet. Pellets were fixed with $2.5 \%$ glutaraldehyde in $0.02 \mathrm{M} \mathrm{PBS}(\mathrm{pH} 7.4)$ at $4^{\circ} \mathrm{C}$ for $4 \mathrm{~h}$ and post-fixed in $1 \%$ osmic acid for $1 \mathrm{~h}$, dehydrated in an ascending acetone series and subsequently embedded in Epon816. Ultrathin 70-nm sections were stained with uranyl acetate and lead citrate. The ultrastructural organization was observed with a JEM-1200EX transmission electron microscope (Jeol, Tokyo, Japan).

Western blot analysis. Following incubation with $4 \mu \mathrm{g} / \mathrm{ml}$ PSI for $48 \mathrm{~h}, \mathrm{PC}-9-\mathrm{ZD}$ cells were collected. Samples containing equal amounts of protein were electrophoresed using $10 \%$ SDS-PAGE, transferred onto polyvinylidene fluoride membranes and then incubated with specific primary antibodies. The blots were reacted with horseradish peroxidase-conjugated secondary antibodies and were detected using the enhanced chemiluminescence system (Santa Cruz Biotechnology, Inc.). The density of the band was quantified by densitometry and exposed to X-ray film (Eastman-Kodak, Rochester, NY, USA) using GAPDH levels as a control.

In vivo xenograft studies and PSI administration. Nude mice were inoculated subcutaneously into the left flank with $\sim 2 \times 10^{6}$ cells. When the xenograft grew to $\sim 15 \mathrm{~mm}$ in diameter for 1-2 weeks, the mice were randomly divided into four groups (six mice/group): The mice in the control group were intramuscularly injected with normal saline and those in the PSI treatment groups received 2, 4 and $8 \mathrm{mg} / \mathrm{kg}$ PSI, respectively, by gavage administration once a day. Tumor growth was measured by ${ }^{18} \mathrm{~F}$-fludeoxyglucose (FDG) microPET scan at the 14th day after administration. At the end of the experiments, the mice were sacrificed.

microPET scanning and data analysis. The tracer ${ }^{18} \mathrm{~F}-\mathrm{FDG}$ was synthesized routinely using an automatic ${ }^{18} \mathrm{~F}-\mathrm{FDG}$ synthesizer (FDG-F100; Sumitomo Heavy Industries, Ltd., Shinagawa, Japan), and the radiochemical purity of the ${ }^{18} \mathrm{~F}-\mathrm{FDG}$ produced was $>99 \%$. Following anesthesia with pentobarbital (35 mg/kg, intraperitoneally), the mice were injected with $0.1 \mathrm{mCi}{ }^{18} \mathrm{~F}-\mathrm{FDG}$ through the tail vein. Mice were placed in a spread prone position on a dedicated holder for scanning. Static acquisition was performed in a three dimensional mode using the microPET imaging system (R4; Concorde Microsystems, Knoxville, TN, USA). A 10-min data collection was performed for ${ }^{18} \mathrm{~F}-\mathrm{FDG}$ microPET with an uptake time of $30 \mathrm{~min}$ after tracer injection. Image reconstruction was performed with attenuation by an ordered subset of expectations of maxima using the posteriori algorithm. Corrections for dead-time and random scattering were also performed. Transaxial, coronal and sagittal computed tomographic slices were then obtained. For semi-quantitative evaluation using the standardized uptake value (SUV), the region of interest (ROI) method was used to evaluate the regional uptake of ${ }^{18} \mathrm{~F}$-FDG. ROIs were drawn around the tumor manually. The mean uptake (percentage injection dose) in the ROI was recorded and calculated automatically. The SUV was calculated as follows: SUV $=$ ROI activity $\mathrm{x}$ mouse weight / injected dose.

Statistical analysis. The experiments were performed in triplicate. Data are presented as the mean \pm standard deviation. Groups were compared using one-way analysis of variance. Differences between the treatment groups were considered significant at $\mathrm{P}<0.05$ or $\mathrm{P}<0.01$.

\section{Results}

PSI inhibits the proliferation of PC-9-ZD cells. PSI inhibited the growth of PC-9-ZD cells in a time- and dose-dependent manner with increasing concentrations from 0.5 to $9 \mu \mathrm{g} / \mathrm{ml}$ and incubation times of 24,48 and $72 \mathrm{~h}$. The $\mathrm{IC}_{50}$ of PSI at 24,48 and $72 \mathrm{~h}$ of incubation was $2.51,2.07$ and $1.53 \mu \mathrm{g} / \mathrm{ml}$, respectively (Fig. 2A). As shown in Fig. 2B, MTT assay revealed that PSI inhibited the growth of PC-9-ZD cells.

PSI modifies the cell cycle in PC-9-ZD cells. Flow cytometric analysis revealed that, after $48 \mathrm{~h}$ of PSI treatment, the cell cycle progression in PC-9-ZD cells was disrupted with an increasing percentage of cells in $\mathrm{G} 2 / \mathrm{M}$ phase (Fig. 3A). The $\mathrm{G} 2 / \mathrm{M}$ phase rates were $10.2 \%$ in the control group and 22.4 , 26.3 and $29.7 \%$ in the PSI-treated (1, 2 and $4 \mu \mathrm{g} / \mathrm{ml})$ groups, respectively (Fig. 3B).

PSI induces apoptosis in PC-9-ZD cells. The ability of PSI to induce apoptosis in PC-9-ZD cells was assessed using the Annexin V/PI method. PSI induced significant concentration-dependent levels of apoptosis in PC-9-ZD cells (Fig. 4A). The apoptosis rate was $0.3 \%$ in the control group as compared with $17.2,20.3$ and $32.2 \%$ in the PSI-treated $(1,2$ and $4 \mu \mathrm{g} / \mathrm{ml}$, respectively) groups after $48 \mathrm{~h}$ of PSI treatment (Fig. 4B). 
A

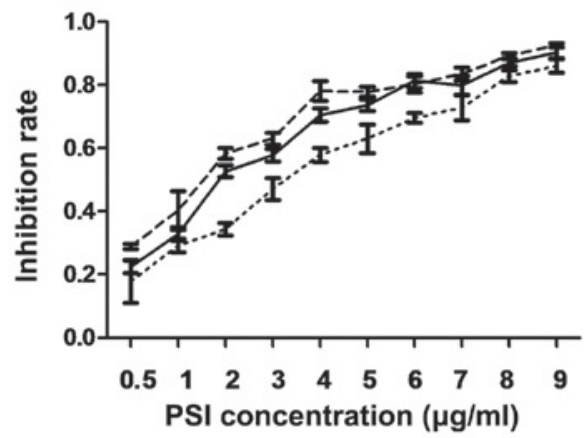

B

… $24 \mathrm{~h}$

$-48 \mathrm{~h}$

$--\cdot 72 \mathrm{~h}$

\section{Control}

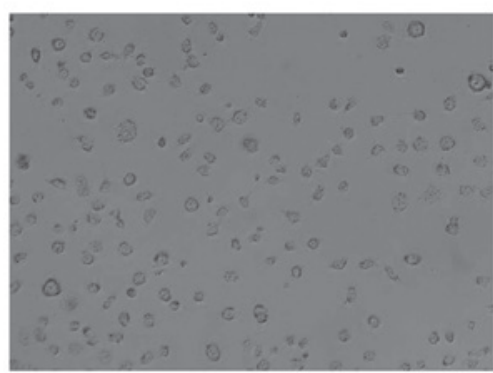

PSI $2 \mu \mathrm{g} / \mathrm{ml}$

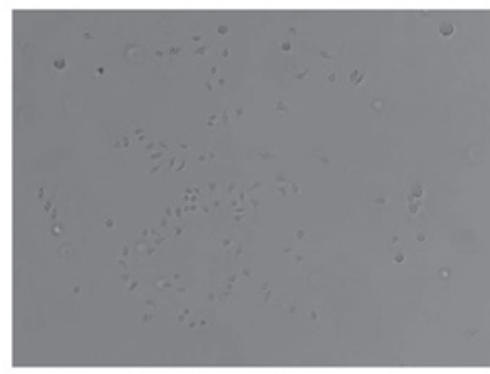

PSI $1 \mu \mathrm{g} / \mathrm{ml}$

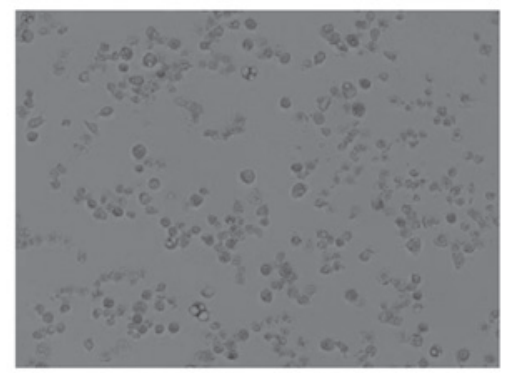

PSI $4 \mu \mathrm{g} / \mathrm{ml}$

Figure 2. PSI-induced growth inhibition of a gefitinib-resistant non-small cell lung cancer cell line following exposure at different concentrations. (A) Inhibition rates were significantly increased in the treatment group compared with those in the control group at the same time-point $(\mathrm{P}<0.01)$ and exhibited a dose-dependent manner. (B) Morphological changes of cells following exposure to PSI at increasing concentrations for $48 \mathrm{~h}$. PSI, Paris saponin I.

A

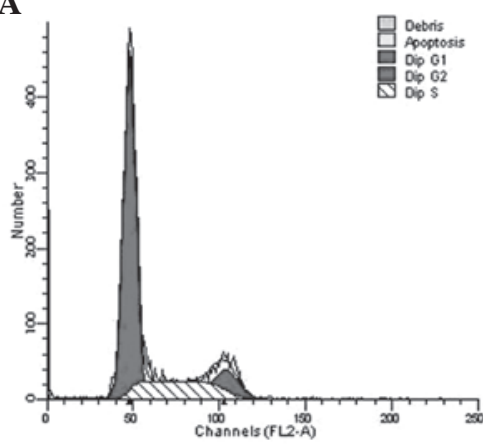

Control

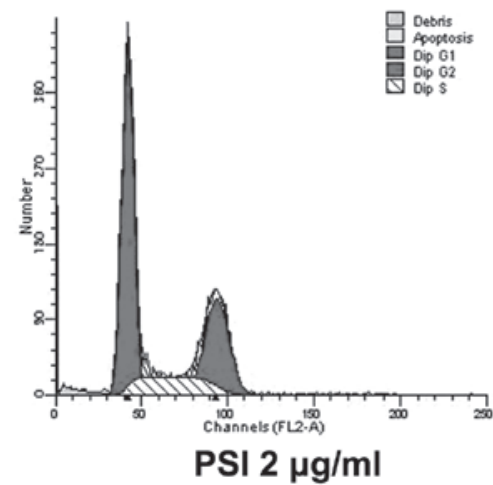

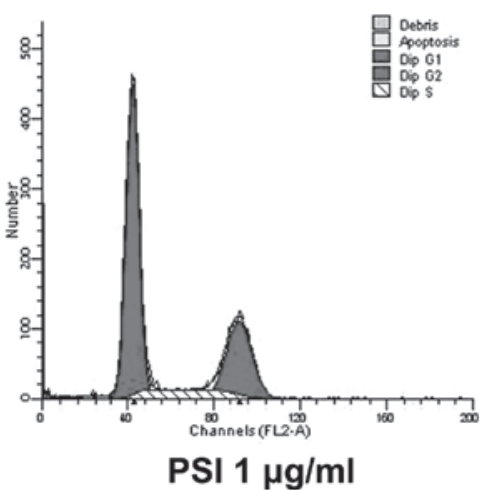

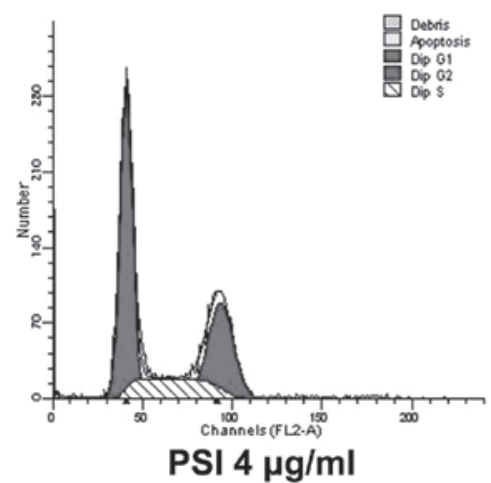

B

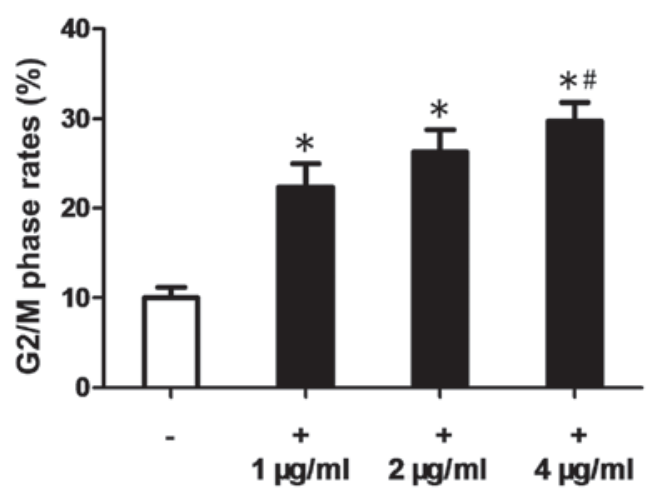

Figure 3. PC-9-ZD cell cycle distribution graphs for different groups. (A) PSI treatment caused G2/M-phase arrest for $48 \mathrm{~h}$ in the PSI-treated (1, 2 and $4 \mu \mathrm{g} / \mathrm{ml}$ ) and control groups. (B) Percentage of cells in G2/M phase at different concentrations of PSI. "Statistically significant difference $(\mathrm{P}<0.01)$ between the treated groups and the control group. "Significantly increased in the $4 \mu \mathrm{g} / \mathrm{ml}$ PSI group compared with the 1 and $2 \mu \mathrm{g} / \mathrm{ml}$ PSI groups (P<0.05, respectively). PSI, Paris saponin I.

Morphology of apoptotic cells. The morphological observation of PSI-induced apoptosis in PC-9-ZD cells using transmission electron microscopy showed cross-sectional features of apoptosis: Cell shrinkage, chromatin condensation, integrity of the plasma membrane, increased cellular granularity, nuclear collapse and continual blebbing and the formation of apoptotic 
A
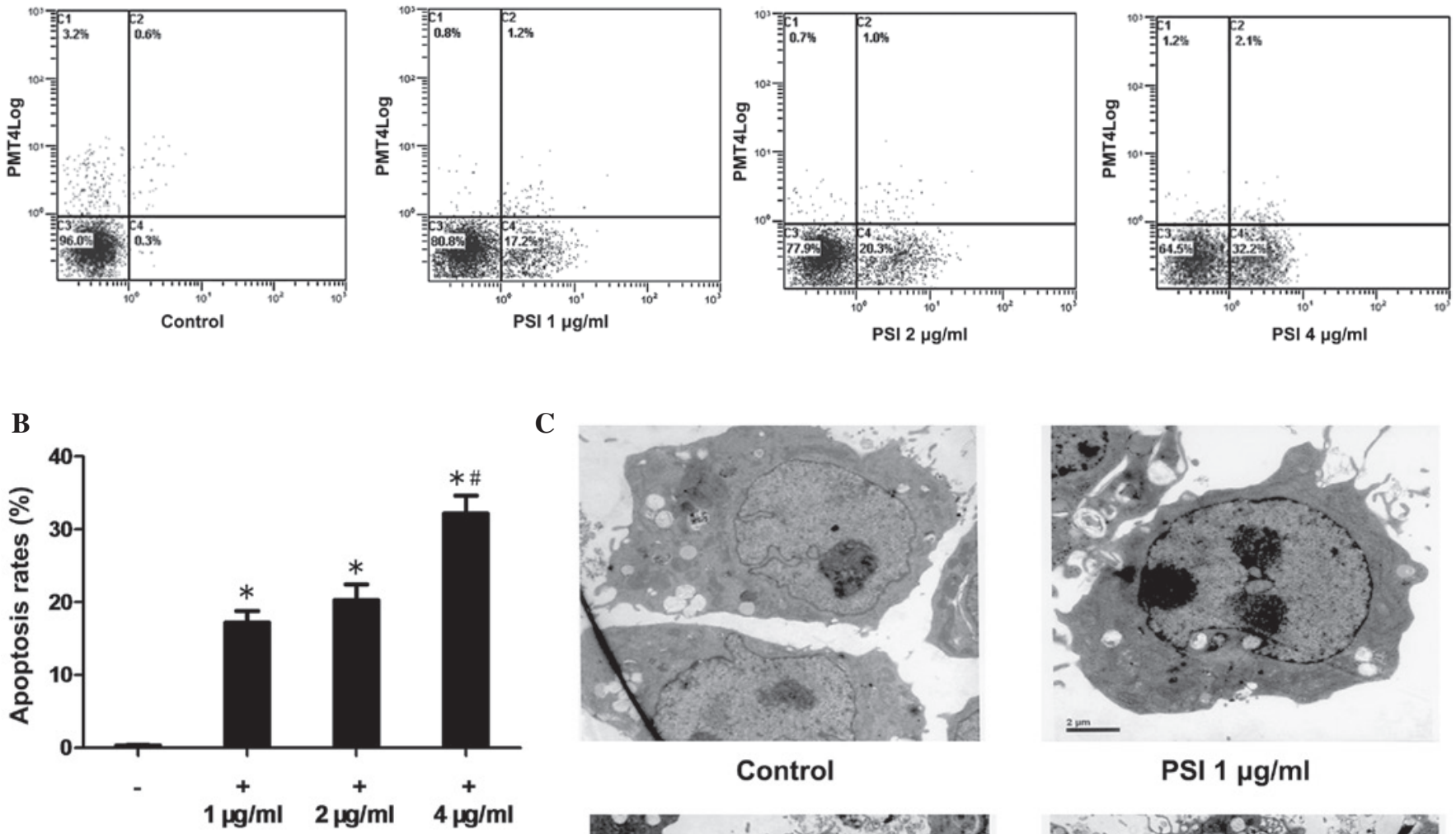

C

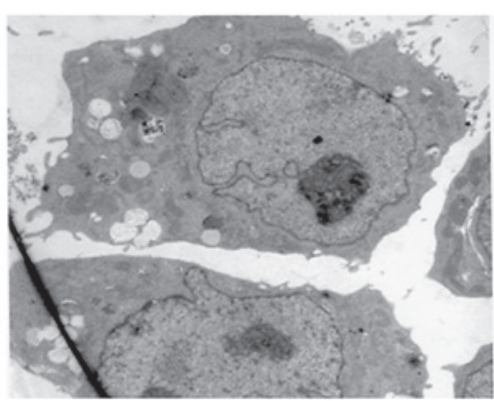

Control

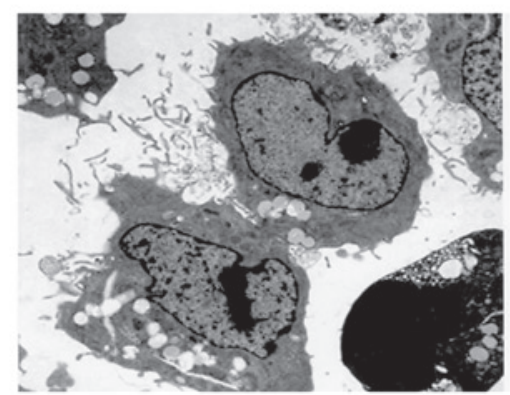

PSI $2 \mu \mathrm{g} / \mathrm{ml}$

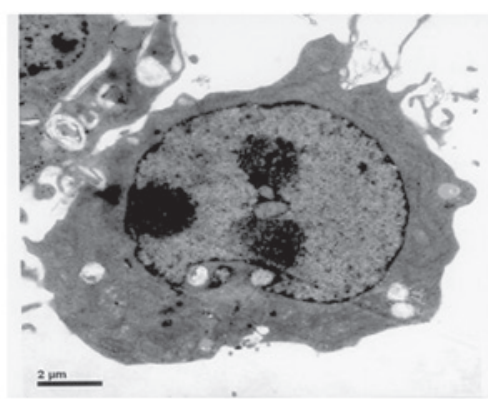

PSI $1 \mu \mathrm{g} / \mathrm{ml}$

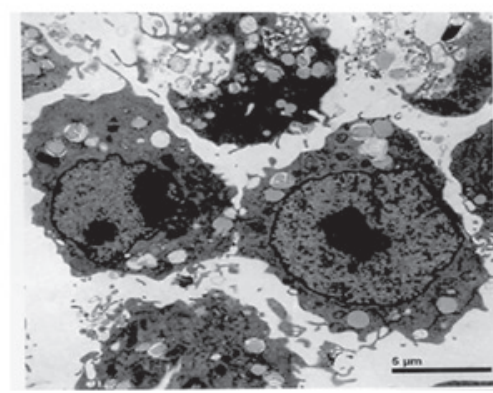

PSI $4 \mu \mathrm{g} / \mathrm{ml}$

Figure 4. Apoptosis induced by PSI. (A) Flow cytometric analysis of apoptosis in the PSI-treated (1, 2 and $4 \mu \mathrm{g} / \mathrm{ml}$ ) and control groups. (B) Percentage of apoptotic cells at different PSI concentrations. "Statistically significant difference $(\mathrm{P}<0.01)$ between the treated groups and the control group. ${ }^{\#}$ Significantly increased in the $4 \mu \mathrm{g} / \mathrm{ml}$ PSI group compared with the 1 and $2 \mu \mathrm{g} / \mathrm{ml}$ PSI groups (all $\mathrm{P}<0.05$ ). (C) Transmission electron microscopy showing cross-sectional features of apoptosis, including cell shrinkage, chromatin condensation, integrity of the plasma membrane, increased cellular granularity, nuclear collapse, continual blebbing and the formation of apoptotic bodies, in the PSI (1,2 and $4 \mu \mathrm{g} / \mathrm{ml})$ groups compared with the control group. PSI, Paris saponin I.

bodies (Fig. 4C). The morphology of apoptotic PC-9-ZD cells was assessed following treatment with 1, 2 and $4 \mu \mathrm{g} / \mathrm{ml}$ PSI for $48 \mathrm{~h}$, respectively.

Effects of PSI on the levels of Bcl-2, Bax and caspase-3 in $P C-9-Z D$ cells. In order to explore potential signaling pathways by which PSI induced apoptosis, western blot analysis was used to evaluate the expression of the $\mathrm{Bcl}-2$ family and caspase- 3 protein. The level of $\mathrm{Bcl}-2$ protein decreased, while the level of Bax protein increased following treatment with PSI for $48 \mathrm{~h}$. The ratio of Bax to $\mathrm{Bcl}-2$ was significantly enhanced. Furthermore, the expression of caspase-3 protein was significantly enhanced (Fig. 5).

PC-9-ZD tumor xenograft glucose metabolism variation and data analysis. ${ }^{18} \mathrm{~F}-\mathrm{FDG}-\mathrm{microPET}$ imaging has been extensively used for diagnosing tumors that exhibit higher metabolic activity than normal tissue. To visualize glucose uptake in tumor xenografts following treatment, ${ }^{18}$ F-FDG-microPET imaging was performed. Compared with muscle tissue with endogenous ${ }^{18} \mathrm{~F}-\mathrm{FDG}$ signals, the uptake by tumors was significantly higher, as shown in Fig. 6A. The microPET imaging data showed that the ${ }^{18} \mathrm{~F}-\mathrm{FDG}$ uptake in the control group was higher than that in the PSI-treated groups; the data are quantitatively summarized in Fig. 6B. This indicates that ${ }^{18} \mathrm{~F}-\mathrm{FDG}$-microPET imaging may not be able to demonstrate the metabolic outcome of tumor growth inhibition.

\section{Discussion}

Lung cancer is by far the leading cause of cancer-related mortality within the United States and throughout the world (24), with a global incidence. There has been much 

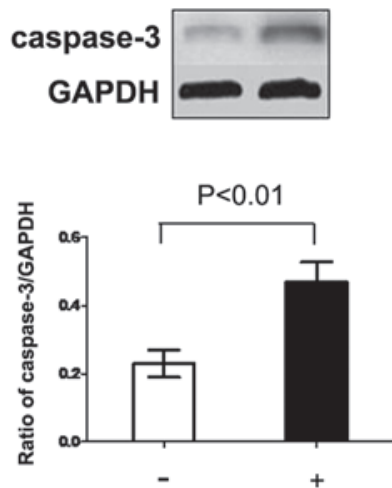
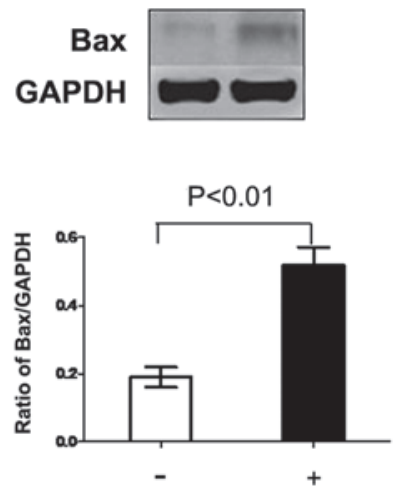
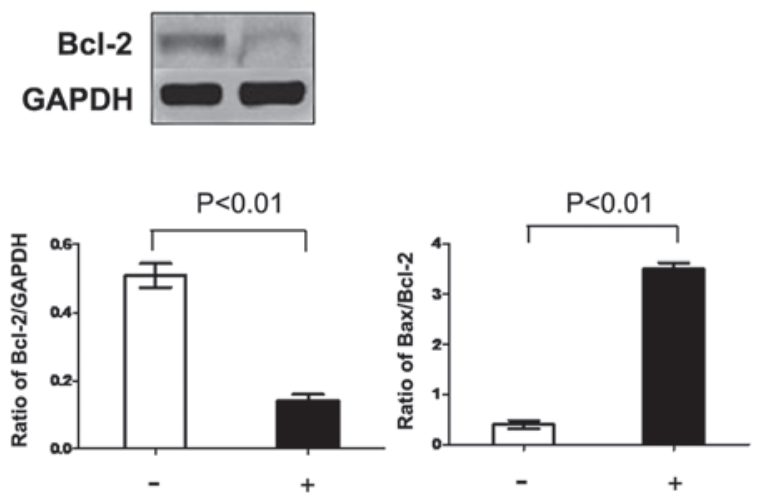

Figure 5. Effect of PSI on levels of caspase-3, Bax and Bcl-2 protein expression in the control and treated groups. Protein levels were detected using western blot analysis. Bar charts show relative protein levels in the treatment and control groups. The concentration of PSI in the treatment group was $4 \mu \mathrm{g} / \mathrm{ml}$. Significant differences in protein levels were observed between the treated and control groups (all $\mathrm{P}<0.01$ ). Bcl-2, B-cell lymphoma 2; Bax, Bcl-2 associated X protein; PSI, Paris saponin I.

A

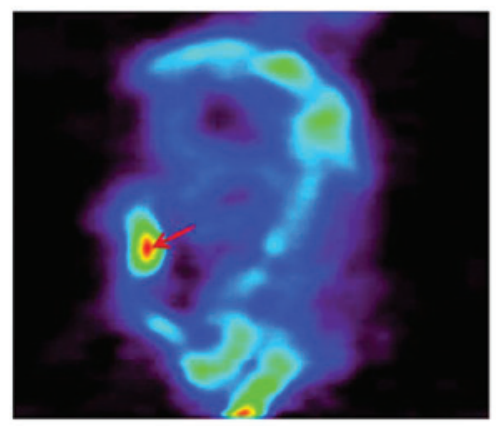

Control

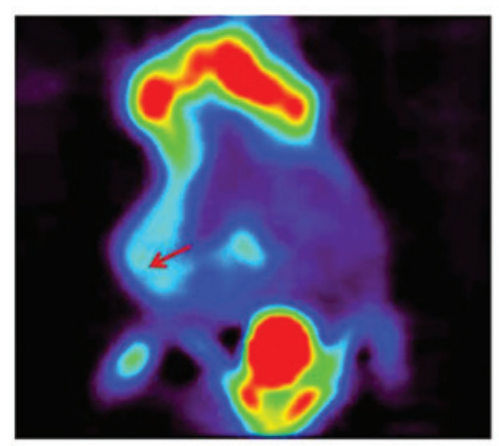

PSI 4 mg/kg

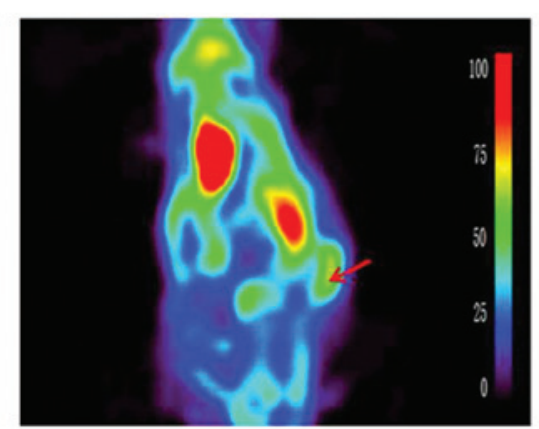

PSI 2 mg/kg

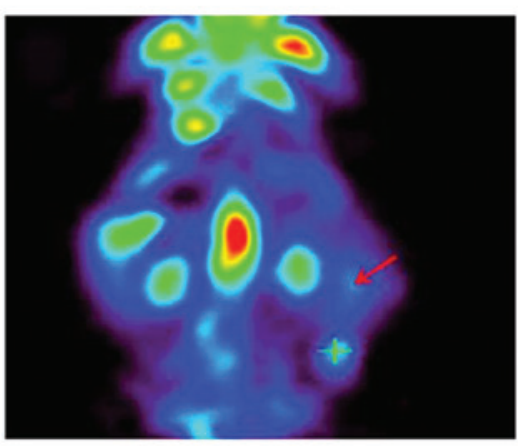

PSI 8 mg/kg
B

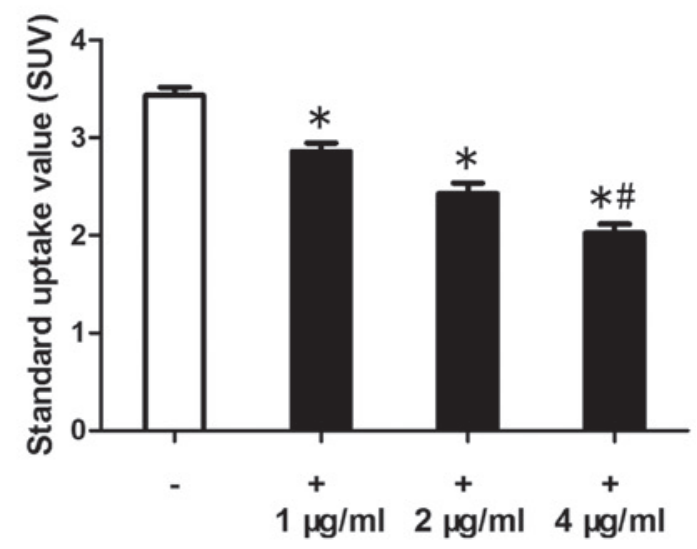

Figure 6. (A) ${ }^{18}$ F-fludeoxyglucose-micro-positron emission tomography scanning images of the activity of the glucose metabolism in tumors of the control group and the 1,2 and $4 \mu \mathrm{g} / \mathrm{ml}(2,4$ and $8 \mathrm{mg} / \mathrm{kg})$ PSI groups after two weeks of treatment. Tumor regions in the nude mice are marked with a red arrow. (B) SUV of the tumors (reflecting glucose metabolism). "SUV in the control group was significantly higher than that in the treated groups (P<0.01). "SUV was significantly lower in the $4 \mu \mathrm{g} / \mathrm{ml}$ PSI group than that in the 1 and $2 \mu \mathrm{g} / \mathrm{ml}$ PSI groups $(\mathrm{P}<0.05)$. PSI, Paris saponin I; SUV, standard uptake value.

progress in the treatment of the disease, which is associated with improved surgical techniques, combined modality treatment of limited-stage NSCLC, improved symptom palliation and moderate but significant improvements in the survival of stage IV of the disease (25). However, further research is required in a field in which only $15-17 \%$ of patients live five years. The role of chemotherapy in the last decade has expanded substantially, with evidence for increases in the median survival at stage IV from four months to 8-10 months, as well as improvements in symptom control (26). Furthermore, progress has been observed in the use of concomitant chemoradiotherapy, which has become the mainstream approach for treating patients with locally advanced NSCLC (27). A trial with cisplatin-based chemotherapy suggested that, for resectable NSCLC (28), the improvements in disease-free and overall survival at five years were by $4-5 \%$ (29). However, with the development and progress of multiple small molecules and monoclonal antibodies targeting important growth factor receptors, oncogenes and tumor-suppressor genes known to be aberrant in lung cancer, there is hope for further incremental improvements in the treatment of this deadly disease. 
Despite the continued decline in cancer mortality rates over recent years, the total number of recorded cancer-related mortalities worldwide continues to slightly increase due to drug resistance (30). Due to the genetic instability of cancer cells, genetic modifications can enable them to acquire a phenotype with resistance to anti-EGFR therapies. In combination, these findings support the importance of understanding the molecular mechanisms affecting cancer cell sensitivity or resistance to such inhibitors. The gefitinib-resistant variant (PC-9-ZD) has been widely investigated (31), and the most relevant mechanisms contributing to the acquisition of sensitivity/resistance to EGFR inhibitors include EGFR gene somatic mutations in exons 18-21 in the EGFR kinase domain and loss of the target, Akt, and inactivating mutations or loss of phosphatase and tensin homolog function. Other mechanisms involve cyclin D1 and cyclin-dependent kinase inhibitor $1 \mathrm{~B}$, which are commonly deregulated in various types of cancer (32).

Preclinical studies have made Paris saponins emerge as promising anti-cancer agents (33-37). PSI exerts a wide range of pharmacological activities, including cytotoxic activity against a number of malignancies, such as NSCLC (38-42). PSI has been approved for cancer therapy as a result of its potential involvement in the suppression of tumor growth.

In the present study, the potential therapeutic effects of PSI were evaluated in a gefitinib-resistant cell line. Cell cycle regulation is important for cell proliferation, and the present study showed that PSI changed the cycle distribution of PC-9-ZD cells, leading to cell cycle arrest in G2/M phase. The G2/M-phase rates were $10.2 \%$ in the control group and 22.4, 26.3 and $29.7 \%$ in the PSI treatment groups $(1,2$ and $4 \mu \mathrm{g} / \mathrm{ml}$, respectively). PSI further increased the rate of apoptosis in PC-9-ZD cells. Rates of apoptosis were $0.3 \%$ in the control group, while they were 17.2, 20.3 and $32.2 \%$ in the PSI treatment groups (1, 2 and $4 \mu \mathrm{g} / \mathrm{ml}$, respectively). This was further verified by transmission electron microscopy, which showed cross-sectional features of apoptosis: Cell shrinkage, chromatin condensation, integrity of plasma membrane, increased cellular granularity, nuclear collapse, continual blebbing and the formation of apoptotic bodies. Caspases are crucial mediators of apoptosis and, among them, caspase- 3 is a frequently activated death protease catalyzing the specific cleavage of numerous cellular key proteins (43). The Bcl-2 family, which comprises both anti-apoptotic (including $\mathrm{Bcl}-2$ and $\mathrm{B}$-cell lymphoma extra large) and pro-apoptotic (including Bax and Bcl-2-homologous antagonist/killer) members, is the main controller and mediator of apoptosis $(44,45)$. In particular, a high Bcl-2/Bax ratio is considered to be a crucial factor of cellular resistance to apoptosis $(46,47)$. Reduced levels of proliferation and enhanced levels of apoptosis are associated with the upregulation of the pro-apoptotic protein Bax (48). In the present study, the protein levels of $\mathrm{Bcl}-2$ were decreased, while those of Bax were increased following treatment with PSI. Furthermore, the expression levels of caspase-3 protein and the ratio of $\mathrm{Bax}$ to $\mathrm{Bcl}-2$ were significantly enhanced following PSI treatment. ${ }^{18} \mathrm{~F}$-FDG-PET is a pharmacodynamic biomarker for the early assessment of the treatment response to drugs in NSCLC xenograft models (49). In the present study, ${ }^{18} \mathrm{~F}-\mathrm{FDG}$ uptake in PSI treatment groups was lower compared with that in the control group.
In conclusion, PSI is a potent antitumor agent that acts by inhibiting Bcl-2 and enhancing the expression of caspase-3 protein, and it should be developed as a natural drug for the therapy of gefitinib-resistant NSCLC.

\section{Acknowledgements}

The present study was supported by grants from the National Natural Science Foundation of China (grant no. 81303274), Wujieping Foundation of China (grant no. 320.6700.09035) and Zhejiang Traditional Medicine Project (grant no. 2011ZZ011). The authors would like to thank Dr Lijinhui from the Department of Chinese Medicine and Rehabilitation at the Second Affiliated Hospital of Zhejiang University School of Medicine for assistance with the analysis of in vivo data.

\section{References}

1. Peters S, Adjei AA, Gridelli C, et al; ESMO Guidelines Working Group: Metastatic non-small-cell lung cancer (NSCLC): ESMO Clinical Practice Guidelines for diagnosis, treatment and follow-up. Ann Oncol (Suppl 7): vii56-vii64, 2012.

2. Yang JJ, Chen HJ, Yan HH, et al: Clinical modes of EGFR tyrosine kinase inhibitor failure and subsequent management in advanced non-small cell lung cancer. Lung Cancer 79: 33-39, 2013.

3. Milella M, Nuzzo C, Bria E, et al: EGFR molecular profiling in advanced NSCLC: a prospective phase II study in molecularly/clinically selected patients pretreated with chemotherapy J Thorac Oncol 7: 672-680, 2012.

4. Maemondo M, Inoue A, Kobayashi K, et al; North-East Japan Study Group: Gefitinib or chemotherapy for non-small-cell lung cancer with mutated EGFR. N Engl J Med 362: 2380-2388, 2010.

5. Fukuoka M, Yano S, Giaccone G, et al: Multi-institutional randomized phase II trial of gefitinib for previously treated patients with advanced non-small-cell lung cancer (The IDEAL 1 Trial). J Clin Oncol 21: 2237-2246, 2003.

6. Kris MG, Natale RB, Herbst RS, et al: Efficacy of gefitinib, an inhibitor of the epidermal growth factor receptor tyrosine kinase, in symptomatic patients with non-small cell lung cancer: a randomized trial. JAMA 290: 2149-2158, 2003.

7. Lin L and Bivona TG: Mechanisms of resistance to epidermal growth factor receptor inhibitors and novel therapeutic strategies to overcome resistance in NSCLC patients. Chemother Res Pract 2012: 817297, 2012.

8. Ji Y, Ma SL, Zhang YP, et al: Combined treatment with TNF-alpha/gefitinib alleviates the resistance to gefitinib in PC-9 cells. Anticancer Drugs 20: 832-837, 2009.

9. Ramalingam S and Sandler AB: Salvage therapy for advanced non-small cell lung cancer: factors influencing treatment selection. Oncologist 11: 655-665, 2006.

10. Grabley S and Thiericke R: Bioactive agents from natural sources: trends in discovery and application. Adv Biochem Eng Biotechnol 64: 101-154, 1999.

11. Xiao X, Bai P, Bui Nguyen TM, et al: The antitumoral effect of Paris Saponin I associated with the induction of apoptosis through the mitochondrial pathway. Mol Cancer Ther 8: 1179-1188, 2009.

12. Sun J, Liu BR, Hu WJ, et al: In vitro anticancer activity of aqueous extracts and ethanol extracts of fifteen traditional Chinese medicines on human digestive tumor cell lines. Phytother Res 21: 1102-1104, 2007.

13. Xiao M, Dai X, He X, et al: Paris saponin I induces G2/M cell cycle arrest and apoptosis in human gastric carcinoma SGC7901 cells. J Huazhong Univ Sci Technolog Med Sci 31: 768-772, 2011.

14. Li Y, Sun Y, Fan L, et al: Paris saponin VII inhibits growth of colorectal cancer cells through Ras signaling pathway. Biochem Pharmacol 88: 150-157, 2014.

15. GuangLie C, WeiShi G, GaiLing H, et al: Effect of paris saponin on antitumor and immune function in U14 tumor-bearing mice. Afr J Tradit Complement Altern Med 10: 503-507, 2013.

16. Li Y, Gu JF, Zou X, et al: The anti-lung cancer activities of steroidal saponins of P. polyphylla Smith var. chinensis (Franch.) Hara through enhanced immunostimulation in experimental Lewis tumor-bearing C57BL/6 mice and induction of apoptosis in the A549 cell line. Molecules 18: 12916-12936, 2013. 
17. Xiao X, Zou J, Bui-Nguyen TM, et al: Paris saponin II of Rhizoma Paridis - a novel inducer of apoptosis in human ovarian cancer cells. Biosci Trends 6: 201-211, 2012.

18. Wen F, Yin H, Chen C, et al: Chemical characteristics of saponins from Paris fargesii var. brevipetala and cytotoxic activity of its main ingredient, paris saponin H. Fitoterapia 83: 627-635, 2012

19. Cheung JY, Ong RC, Suen YK, et al: Polyphyllin D is a potent apoptosis inducer in drug-resistant HepG2 cells. Cancer Lett 217: 203-211, 2005.

20. Chan JY, Koon JC, Liu X, et al: Polyphyllin D, a steroidal saponin from Paris polyphylla, inhibits endothelial cell functions in vitro and angiogenesis in zebrafish embryos in vivo. J Ethnopharmacol 137: 64-69, 2011.

21. Xiao M, Dai X, He X, et al: Paris saponin I induces $G_{2} / M$ cell cycle arrest and apoptosis in human gastric carcinoma SGC7901 cells. J Huazhong Univ Sci Technolog Med Sci 31: 768-772, 2011.

22. Yang B, Johnson TS, Thomas GL, et al: A shift in the Bax/Bcl-2 balance may activate caspase- 3 and modulate apoptosis in experimental glomerulonephritis. Kidney Int 62: 1301-1313, 2002.

23. Marneros AG, Grossman ME, Silvers DN, et al: Pralatrexate-induced tumor cell apoptosis in the epidermis of a patient with HTLV-1 adult T-cell lymphoma/leukemia causing skin erosions. Blood 113: 6338-6341, 2009.

24. Smith W and Khuri FR: The care of the lung cancer patient in the 21st century: a new age. Semin Oncol 31 (2 Suppl 4): 11-15 2004.

25. Pfister DG, Johnson DH, Azzoli CG, et al; American Society of Clinical Oncology: American Society of Clinical Oncology treatment of unresectable non-small-cell lung cancer guideline: update 2003. J Clin Oncol 22: 330-353, 2004.

26. Gerber DE and Schiller JH: Maintenance chemotherapy for advanced non-small-cell lung cancer: new life for an old idea. J Clin Oncol 31: 1009-1020, 2013.

27. Videtic GM: Locally advanced non-small cell lung cancer: what is the optimal concurrent chemoradiation regimen? Cleve Clin J Med 79 (Suppl 1): eS32-eS37, 2012.

28. Bonomi M, Pilotto S, Milella M, et al: Adjuvant chemotherapy for resected non-small-cell lung cancer: future perspectives for clinical research. J Exp Clin Canc Res 30: 115, 2011.

29. Saintigny P and Burger JA: Recent advances in non-small cell lung cancer biology and clinical management. Discov Med 13: 287-297, 2012

30. Jemal A, Murray T, Samuels A, et al: Cancer statistics, 2003. CA Cancer J Clin 53: 5-26, 2003.

31. Morgillo F, Bareschino MA, Bianco R, et al: Primary and acquired resistance to anti-EGFR targeted drugs in cancer therapy. Differentiation 75: 788-799, 2007.

32. Morgillo F, Cantile F, Fasano M, et al: Resistance mechanisms of tumour cells to EGFR inhibitors. Clin Transl Oncol 11: $270-275,2009$
33. Wang Y, Zhang YJ, Gao WY and Yan LL: Anti-tumor constituents from Paris polyphylla var. yunnanensis. Zhongguo Zhong Yao Za Zhi 32: 1425-1428, 2007 (In Chinese).

34. Sun J, Liu BR, Hu WJ, et al: In vitro anticancer activity of aqueous extracts and ethanol extracts of fifteen traditional Chinese medicines on human digestive tumor cell lines. Phytother Res 21: 1102-1104, 2007.

35. Lee MS, Yuet-Wa JC, Kong SK, et al: Effects of polyphyllin D, a steroidal saponin in Paris polyphylla, in growth inhibition of human breast cancer cells and in xenograft. Cancer Biol Ther 4: 1248-1254, 2005.

36. Cheung JY, Ong RC, Suen YK, et al: Polyphyllin D is a potent apoptosis inducer in drug-resistant HepG2 cells. Cancer Lett 217: 203-211, 2005

37. Siu FM, Ma DL, Cheung YW, et al: Proteomic and transcriptomic study on the action of a cytotoxic saponin (Polyphyllin D): induction of endoplasmic reticulum stress and mitochondria-mediated apoptotic pathways. Proteomics 8: 3105-3117, 2008

38. Jiang H, Su D and Ma SL: The effect of Chonglou Saponin I on proliferation and apoptosis in lung adenocarcinoma cell line PC9. J Chin Oncol 18: 166-169, 2012 (In Chinese).

39. Hua YH, Ma SL, Fu ZF, et al: Effect of Polyphyllin I on radiosensitivity in nasopharyngeal carcinoma cell line CNE-2 in vitro. Chin Arch Trad Chin Med 29: 1387-1390, 2011 (In Chinese).

40. Xiao M,Dai X,He X, et al: Paris saponin I induces G2/M cell cycle arrest and apoptosis in human gastric carcinoma SGC7901 cells. J Huazhong Univ Sci Technolog Med Sci 31: 768-772, 2011.

41. Xiao X, Bai P, Bui Nguyen TM, et al: The antitumoral effect of Paris Saponin I associated with the induction of apoptosis through the mitochondrial pathway. Mol Cancer Ther 8: 1179-1188, 2009.

42. Yan LL, Zhang YJ, Gao WY, et al: In vitro and in vivo anticancer activity of steroid saponins of Paris polyphylla var. yunnanensis. Exp Oncol 31: 27-32, 2009.

43. Porter AG and Jänicke RU: Emerging roles of caspase-3 in apoptosis. Cell Death Differ 6: 99-104, 1999.

44. Hengartner MO: The biochemistry of apoptosis. Nature 407: 770-776, 2000.

45. Shroff EH, Snyder C and Chandel NS. Bcl-2 family members regulate anoxia-induced cell death. Antioxid Redox Signal 9: 1405-1409, 2007

46. Reed JC, Miyashita T, Takayama S, et al: BCL-2 family proteins: regulators of cell death involved in the pathogenesis of cancer and resistance to therapy. J Cell Biochem 60: 23-32, 1996.

47. Sedlak TW, Oltvai ZN, Yang E, et al: Multiple Bcl-2 family members demonstrate selective dimerizations with Bax. Proc Natl Acad Sci USA 92: 7834-7838, 1995.

48. Xu F, Tian Y, Huang Y, et al: EGFR inhibitors sensitize non-small cell lung cancer cells to TRAIL-induced apoptosis. Chin J Cancer 30: 701-711, 2011.

49. Mudd SR, Voorbach MJ, Reuter DR, et al: FDG-PET as a pharmacodynamic biomarker for early assessment of treatment response to linifanib (ABT-869) in a non-small cell lung cancer xenograft model. Cancer Chemother Pharmacol 69: 1669-1672, 2012. 